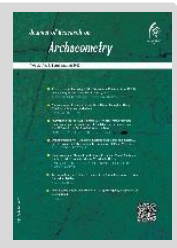

Technical Note

\title{
Using Dynamic Pulse Function for Semantic 3D modeling of Historical Landmarks
}

\author{
Behnam Alizadehashrafi ${ }^{\star}$, Samad Roohi
}

Multimedia Department, Tabriz Islamic Art University, Tabriz, IRAN

\author{
Received: 15/04/2019
}

Accepted: 21/06/2019

\begin{abstract}
The pulse function (PF) is a technique based on procedural preprocessing system to generate a computerized virtual photo of the façade with in a fixed square size. Dynamic Pulse Function (DPF) is an enhanced version of PF which can create the final photo, proportional to real geometry. This can avoid distortion while projecting the computerized photo on the generated 3D model. The challenging issue that might be handled for having 3D model in LoD3 rather than LOD2, is the final aim that have been achieved in this paper. In this research the parameters of Dynamic Pulse Functions are utilized via Ruby programming language in SketchUp Trimble to generate (exact position and deepness) the windows and doors automatically in LoD3 based on the same concept of DPF. The advantage of this technique is automatic generation of huge number of similar geometries e.g. windows by utilizing parameters of DPF along with defining entities and window layers. In case of converting the SKP file to CityGML via FME software or CityGML plugins the 3D model contains the semantic database about the entities and window layers which can connect the CityGML to MySQL. The concept behind DPF, is to use logical operations to project the texture on the background image which is dynamically proportional to real geometry. The process of projection is based on two vertical and horizontal dynamic pulses starting from upper-left corner of the background wall in down and right directions respectively based on image coordinate system. The logical one/zero on the intersections of two vertical and horizontal dynamic pulses projects/does not project the texture on the background image. It is possible to define priority for each layer. For instance the priority of the door layer can be higher than window layer which means that window texture cannot be projected on the door layer. Orthogonal and rectified perpendicular symmetric photos of the $3 \mathrm{D}$ objects that are proportional to the real façade geometry must be utilized for the generation of the output frame for DPF. The DPF produces very high quality and small data size of output image files in quite smaller dimension compare with the photorealistic texturing method. The disadvantage of DPF is its preprocessing method to generate output image file rather than online processing to generate the texture within the $3 \mathrm{D}$ environment such as CityGML. Furthermore the result of DPF can be utilized for 3D model in LOD2 rather than LOD3. In the current work the random textures of the window layers are created based on parameters of DPF within Ruby console of SketchUp Trimble to generate the deeper geometries of the windows and their exact position on the façade automatically along with random textures to increase Level of Realism (LoR). As the output frame in DPF is proportional to real geometry (height and width of the façade) it is possible to query the XML database and convert them to units such as meter automatically. In this technique, the perpendicular terrestrial photo from the façade is rectified by employing projective transformation based on the frame which is in constrain proportion to real geometry. The rectified photos which are not suitable for texturing but necessary
\end{abstract}

*Corresponding author: b.alizadehashrafi@tabriziau.ac.ir 
for measuring, can be resized in constrain proportion to real geometry before measuring process. Height and width of windows, doors, horizontal and vertical distance between windows from upper left corner of the photo dimensions of doors and windows are parameters that should be measured to run the program as a plugins in SketchUp Trimble. The system can use these parameters and texture file names and file paths to create the façade semi-automatically. To avoid leaning geometry the textures of windows, doors, etc, should be cropped and rectified from perpendicular photos, so that they can be used in the program to create the whole façade along with its geometries. Texture enhancement should be done in advance such as removing disturbing objects, exposure setting, left-right up-down transformation, and so on. In fact, the quality, small data size, scale and semantic database for each façade are the prominent advantages of this method.

Keywords: Random Textures, Historical Landmarks, Dynamic Pulse Function, Automatic 3D Location based Semantic Modeling 


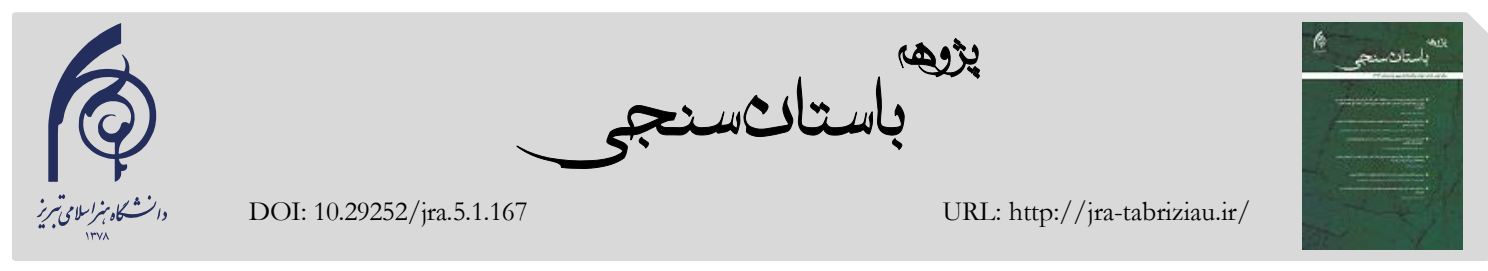

يادداشت فنى

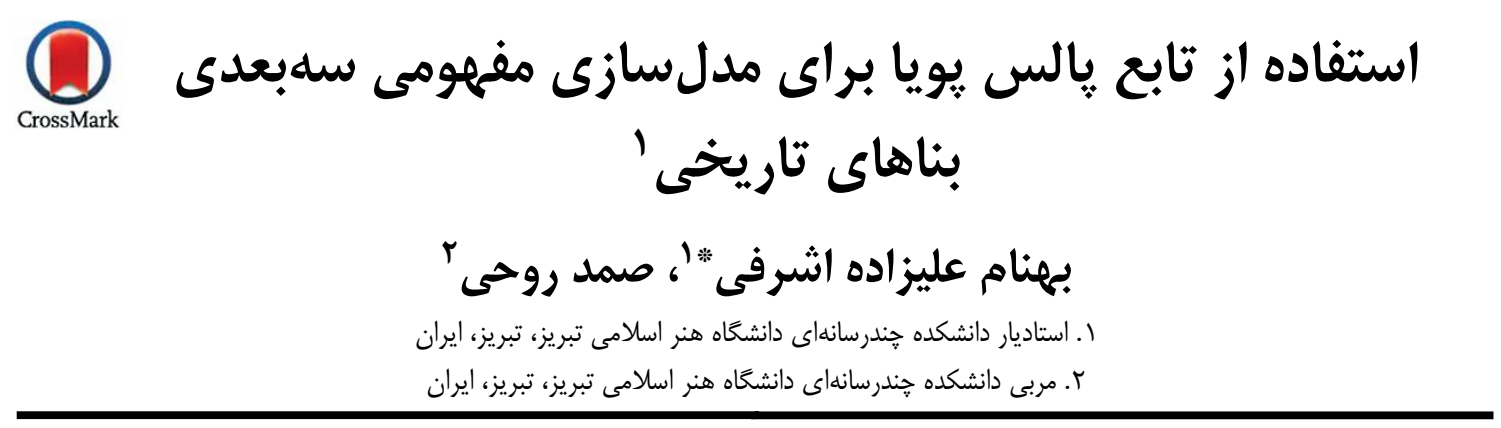

تابع ֶالس يويا (Dynamic Pulse Function) (DPF) نسخه بهبوديافتهاى از (Pulse Function) PF است. اين تابع تصوير نهـايى را

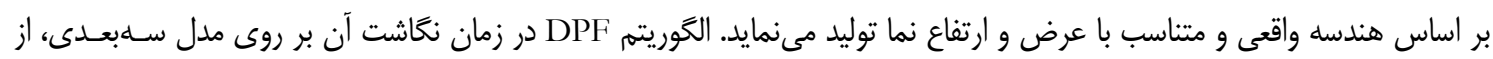

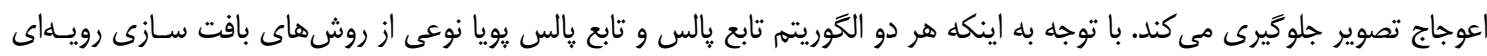

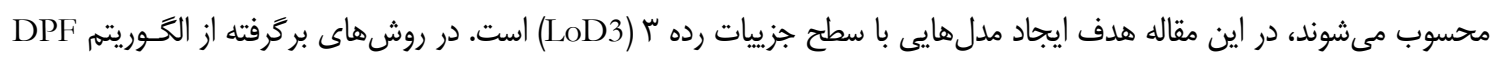

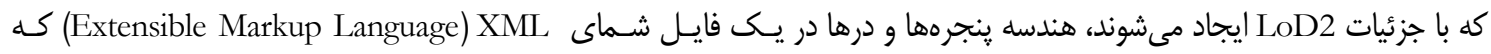

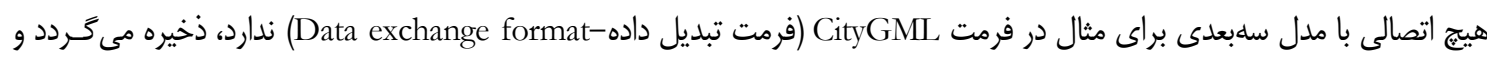

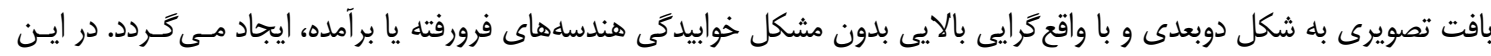

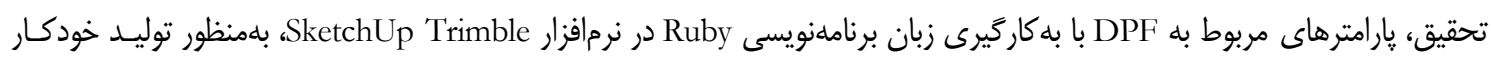

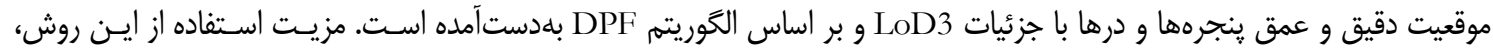

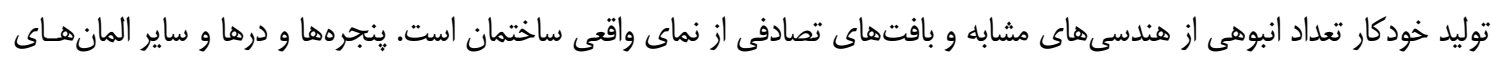

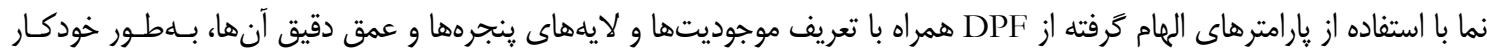
ايجاد مى

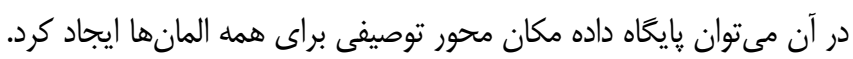

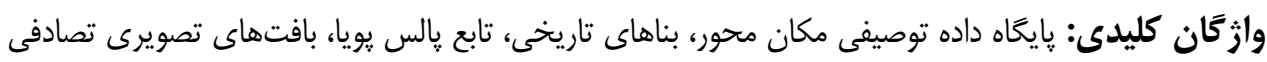

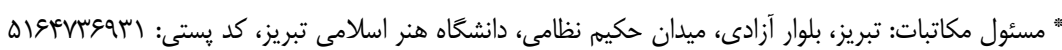
آدرس الكترونيكى: b.alizadehashrafi@tabriziau.ac.ir

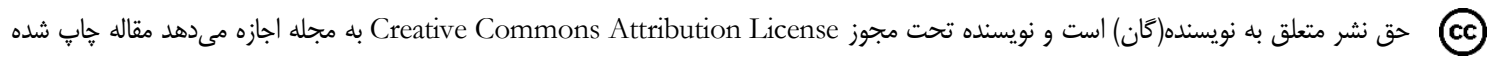

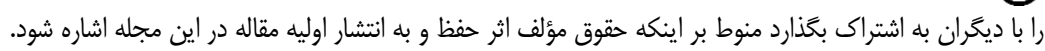


را توليد و انتشـار داده و انعكـاس آن را ثبـت مسىكنتـد، تحت عنوان سنجش از راه دور فعـال ( Active Remote (Sensing

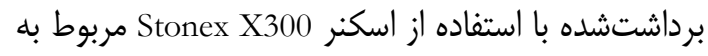

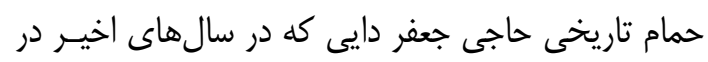

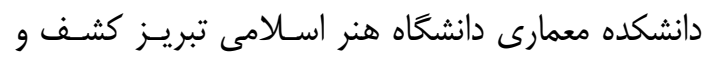
مرمتشده است را نشان مى دهد.

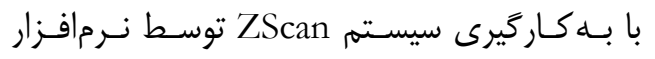
Menci

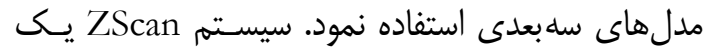

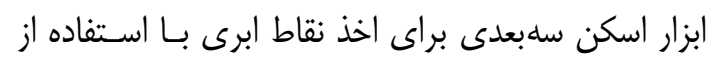

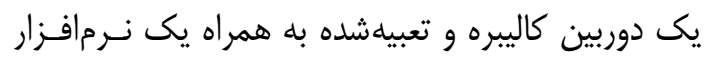
اسـتفادهــده در تطبيـق تصـاوير (Image Matching) است كه از روشهاى سنجش از راه دور از نوع غيرفعال

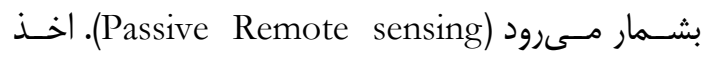
تصاوير با انتقال دوربين بر روى يكى نوار كاليبره شده در

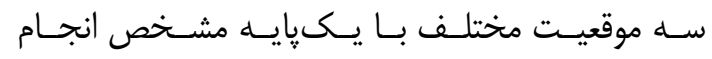

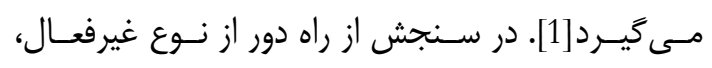

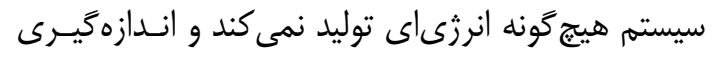

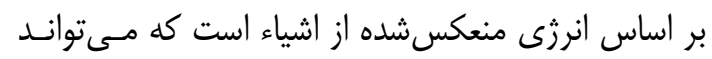

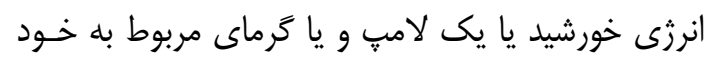

( ) - إ مقدمه

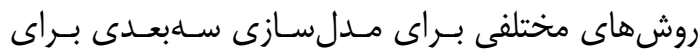

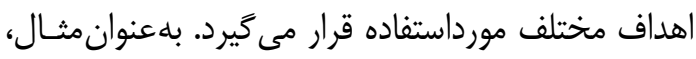
بهمنظور داشتن مدل هاى سلبعدى با دقت بسيار بـالا از باز

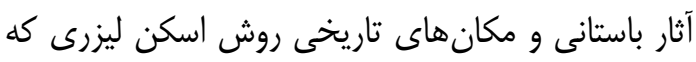

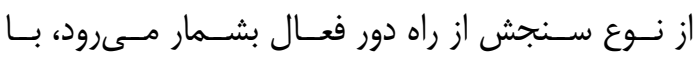

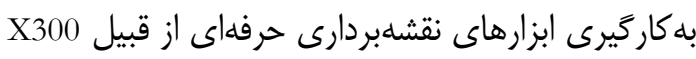
7000i و و Trimble (Mensi) GS200، Stonex Imaging Total station TopCon

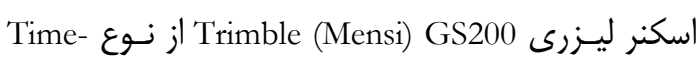

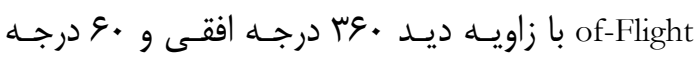

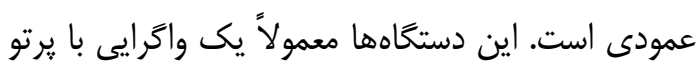

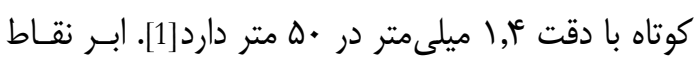

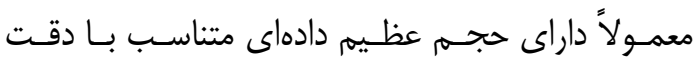

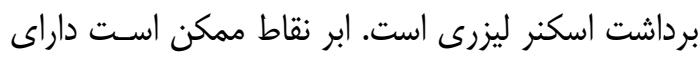

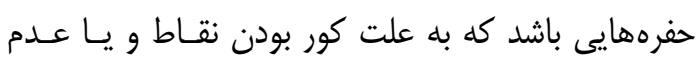

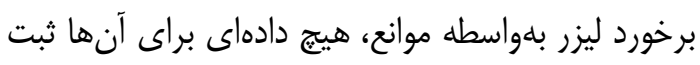

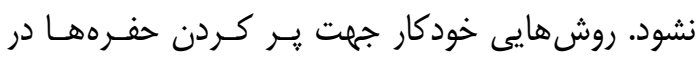

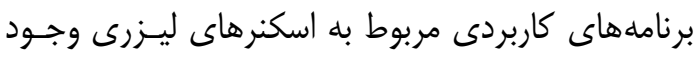

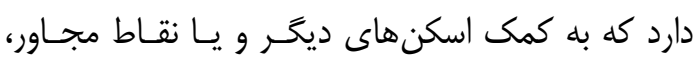
انجام مى گيرد. كليه دستخاههايى كه هر نوعى از انـرزى دئى

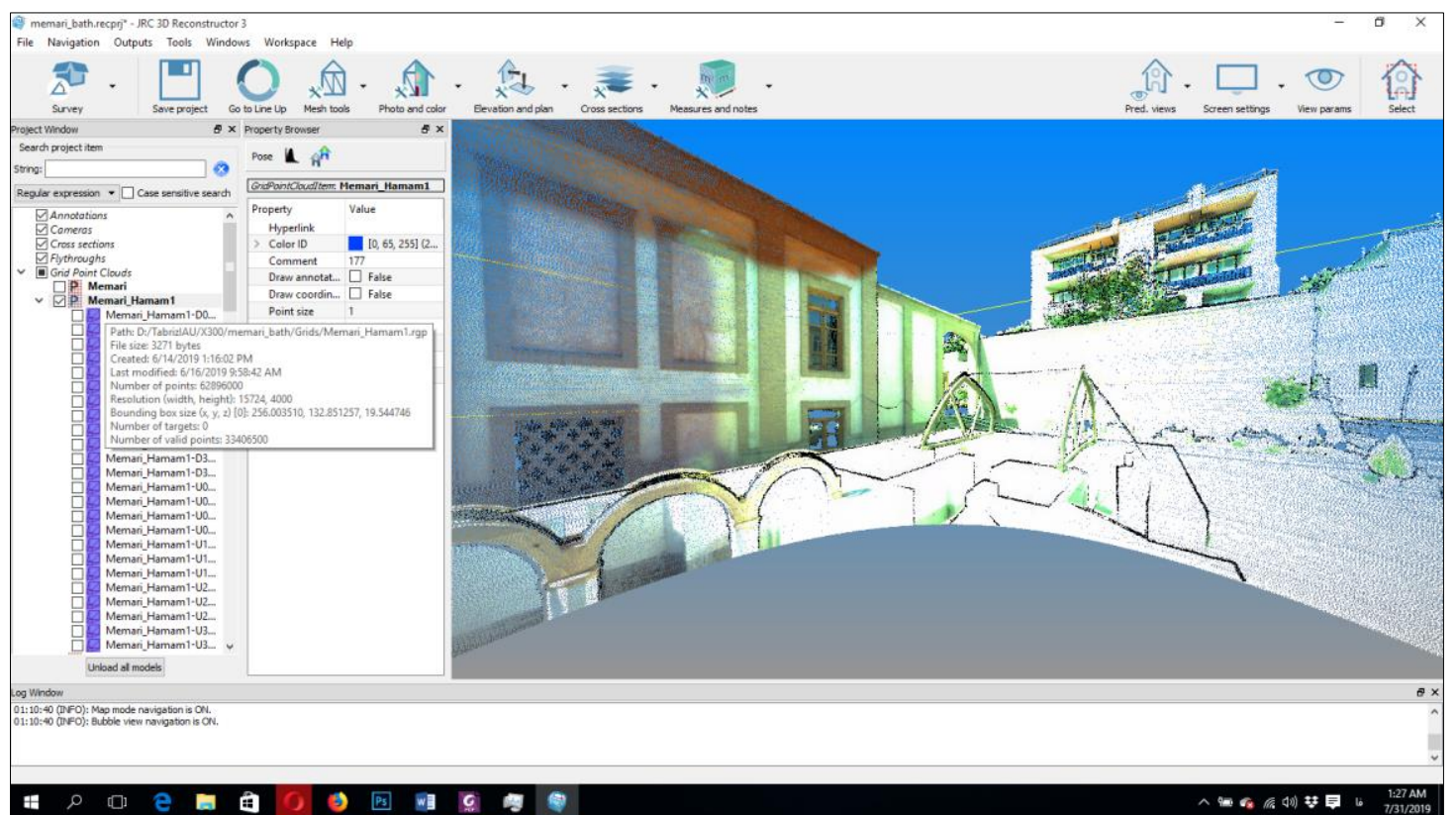

شكل ا: ابر نقاط مربوط به حمام تاريخى حاجى جعفر دائى (62896000 points) (سنجش از راه دور فعال) Fig. 1: The point clouds of historical Hji Jafar Daei Bath via active RS 
شده كه بلطور دايرهوار حول شى موردنظر كَرفتهشدهاند، بهره برد. علاوه بر دوربينهاى حرفهاى، در اين نرمافزار

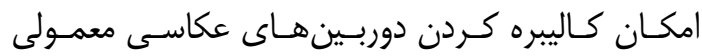
ديجيتال وجود دارد. بهعنوانمثال با استفاده از هأ تصوير از زواياى مختلف كه با كوشى هوشـمند

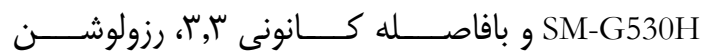

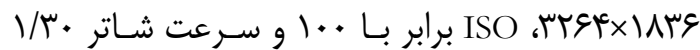

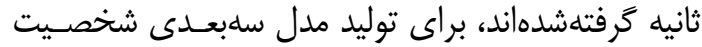

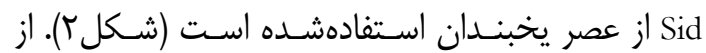

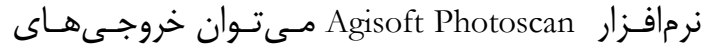
مختلفى با فرمتهـاى سـابعـدى مانتــ COLLODA،

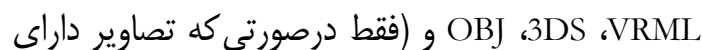
موقعيت جغرافيايى باشند) KMZ را براى بهكـاركيرى در كاربردهاى مختلف مانند موتور بازى يـونيتى يـا كوخـل

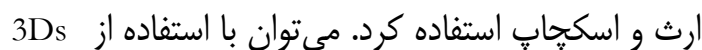

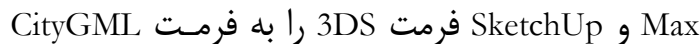

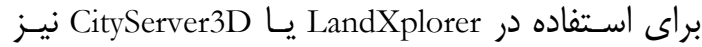

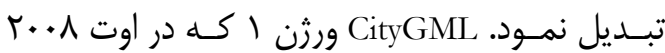
معرفى كرديد، نسخه سلبعدى GML اسـت و نسـخه

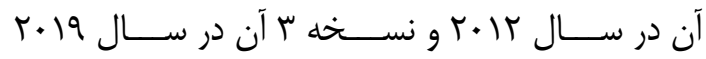

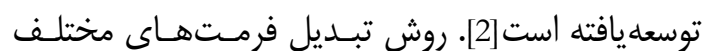

اشياء مانند دوربينهاى مادونقرمز ديد در شـب باشـد.

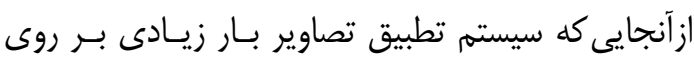

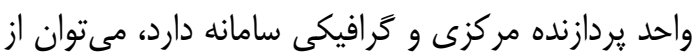

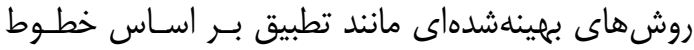
ايبيـولار (Epippolar geometry) كـه قـادر بــانه انجـام تطبيق تصاوير در يك بعـد (بـهــاى تطبيـق دوبعـدى)

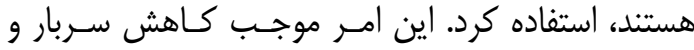

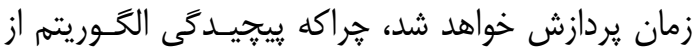

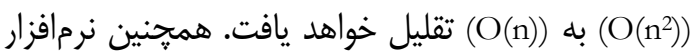

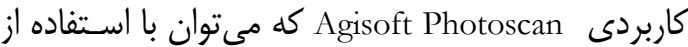

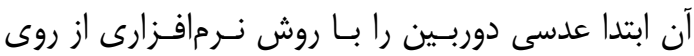

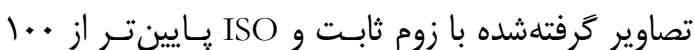

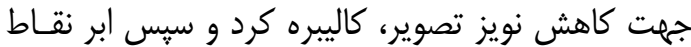

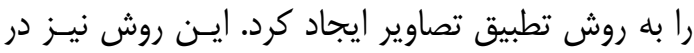

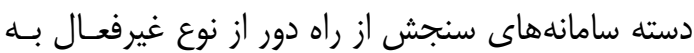

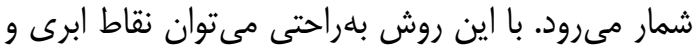

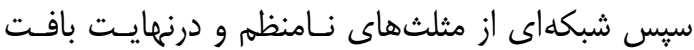
تصويرى كه تركيبى از كليه تصاوير است، را ايجاد كـرد

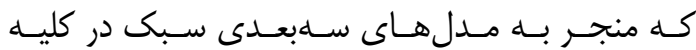

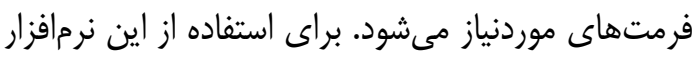
بهراحتى مىتوان از تصاوير دوربينهاى حرفهاى كاليبره

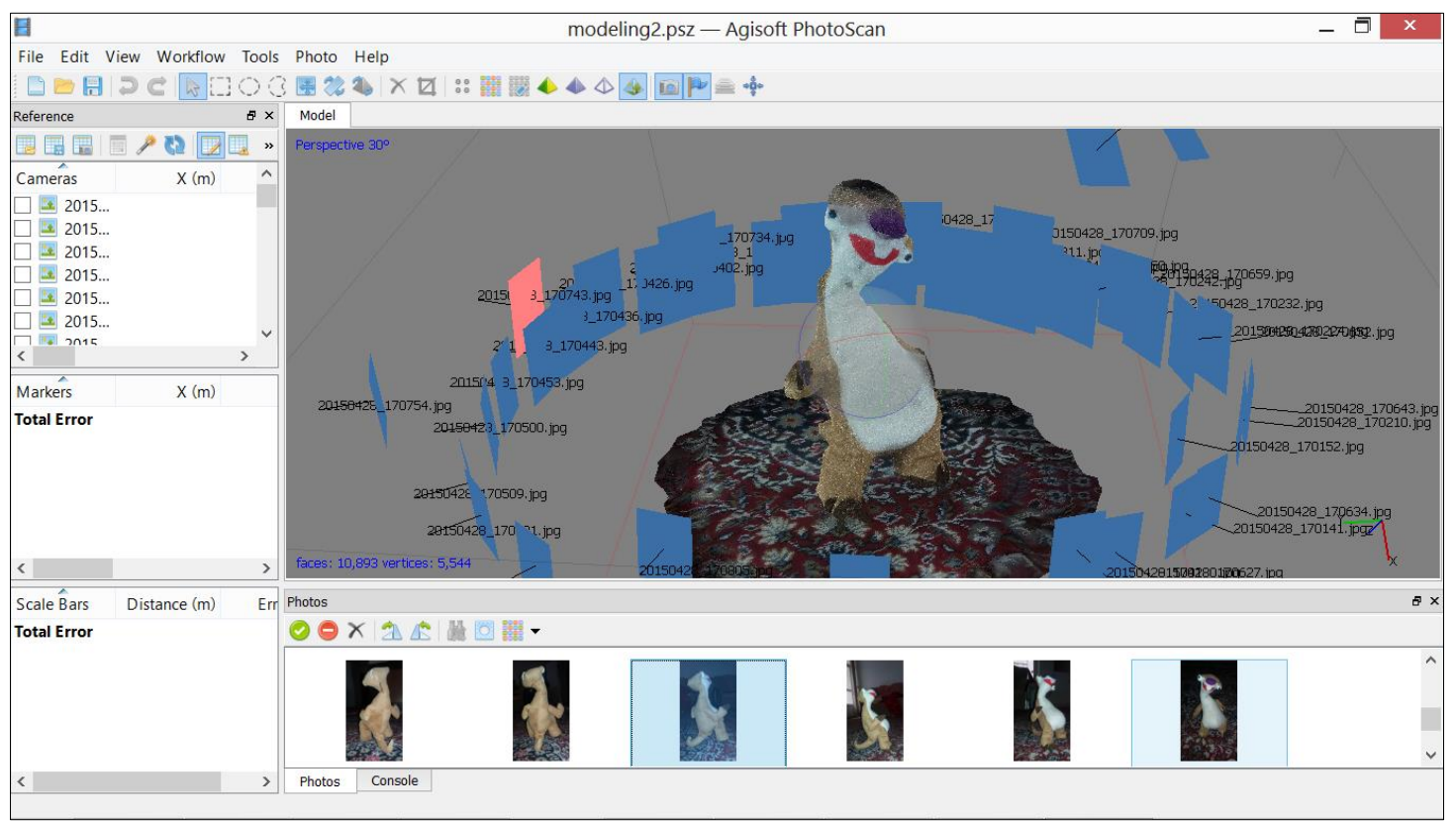

شكل r: مدل سلبعدى شخصيت Sid در يويانمايى عصر يخبندان

Fig. 2: The 3D model of Sid character in ICE age animation 


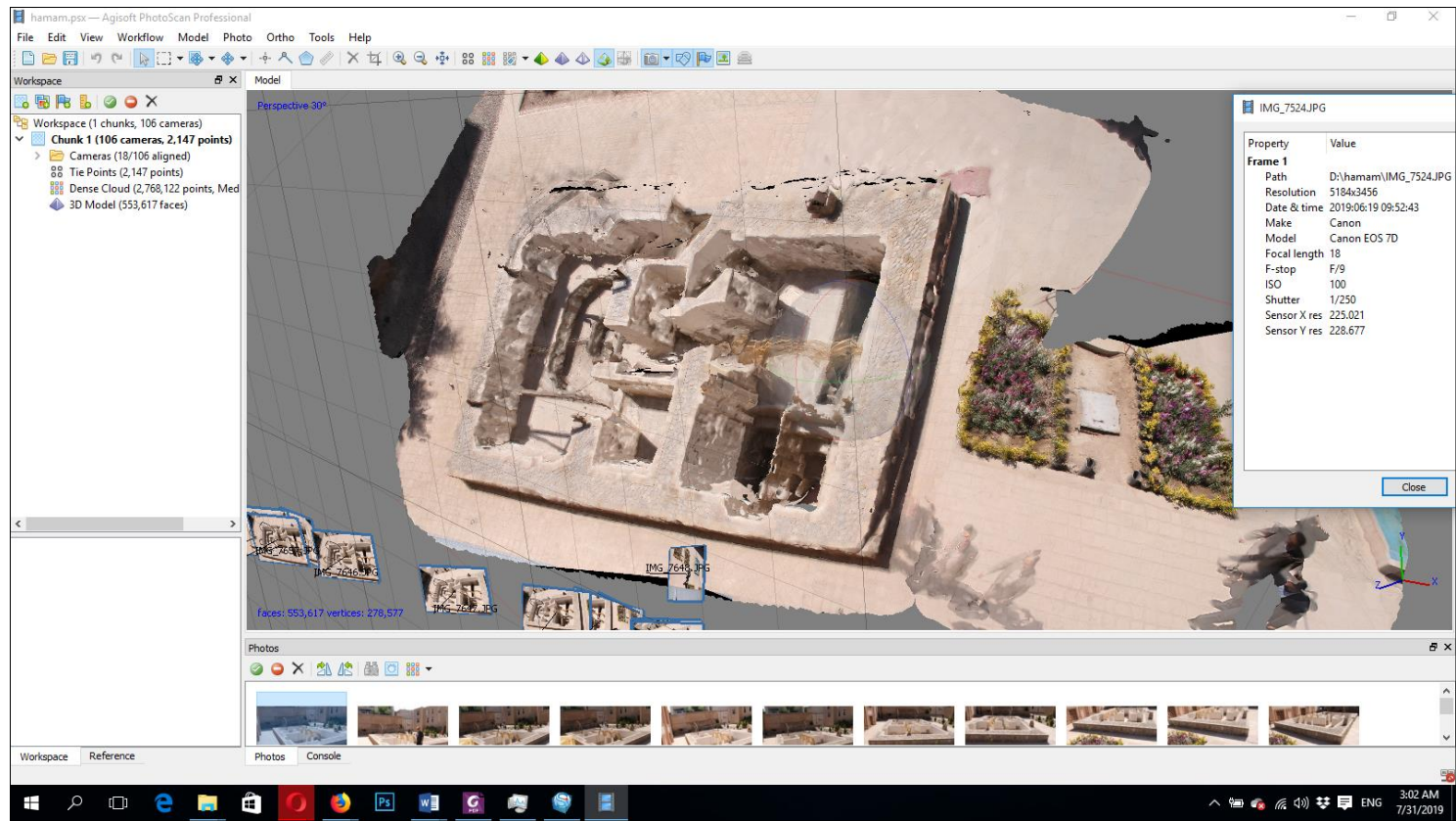

شكل سّ: مدل سلبعدى حمام تاريخى حاجى جعفر دايى با استفاده از نرمافزار AgiSoft Photoscan (سنجش از راه دور غيرفعال) Fig. 3: The 3D model historical Hji Jafar Daei bath via Agisoft Photoscan (Passive RS)

مى سازد. در اين ساختار امكان جسـتجوى نـام افـراد در يايڤاه داده وجود دارد و مدل سلبعدى ساختمانى كـه در

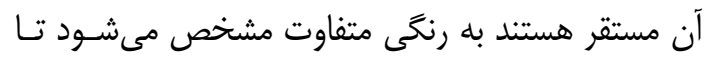

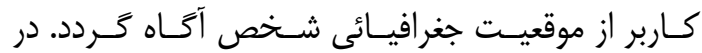

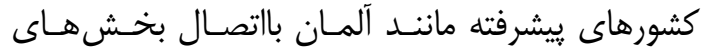
مختلف شهر سهبعدى به حسكَرهاى مختلف توانستهانـا

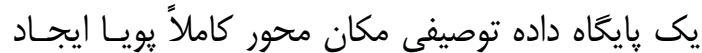

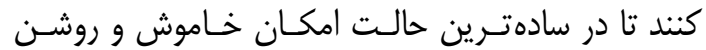

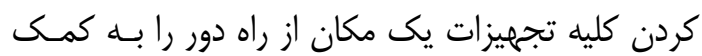

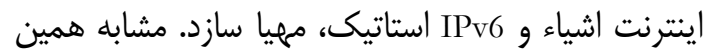

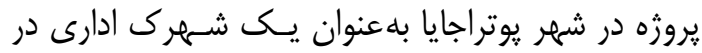

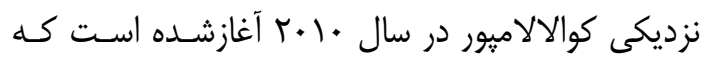

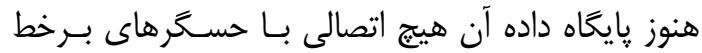
ندارند و فقط داراى پاييخاه داده توصـيفى آفلايـن اسـتـ

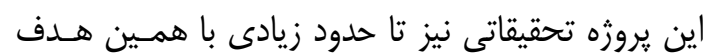

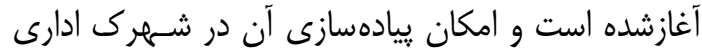
استان اردبيل و يا مكانهاى تاريخى شهر تبريز و اردبيل

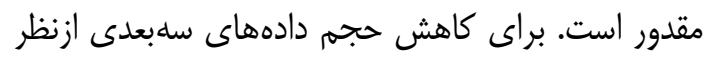
بافتهاى تصويرى و هندسه آنها، استفاده از روشهاى داء تابع يالس :ويا مىتواند ثمربخش باشد[3].
به CityGML با استفاده از يلاكَين CityGML در محيط SketchUp

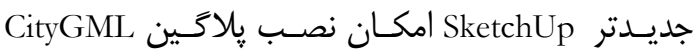

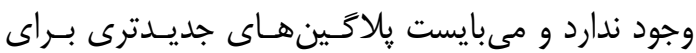
نسخههاى جديدتر در محـيط Ruby بـر زيايـه اسـتاندارد

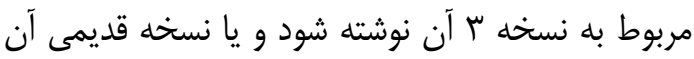
بازنخرى و توسعه يابد.

در شكل س نيز حمام تاريخى حاجى جعفر دايسى بــاــا

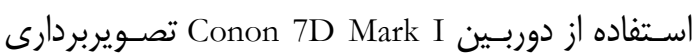
شده است و سبيس با استفاده از و.ا تصوير و نـرمافـزار AgiSoft

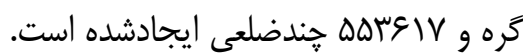

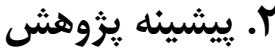

تاكنون روشهاى زيادى براى مدل سازى سـهبعـدى در

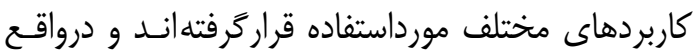

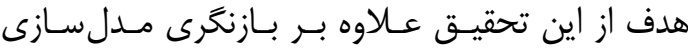

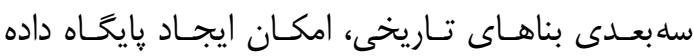

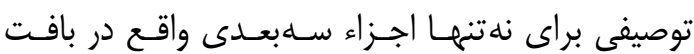
شهرى بلكه ساختمانها و افراد موجود در آنها را مهيـا 


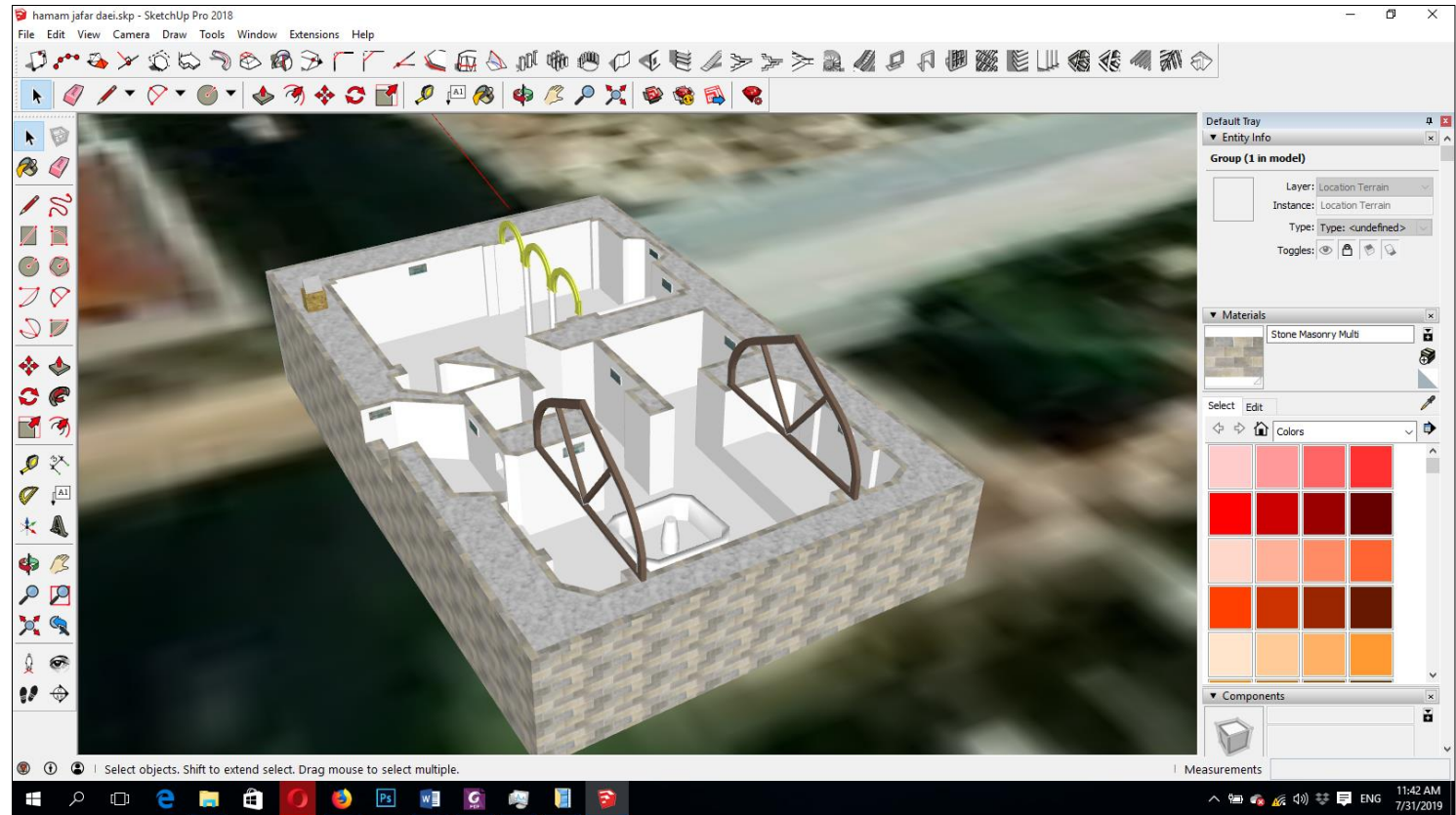

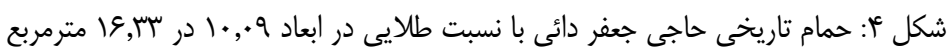

Fig. 4: Historical Hji Jafar Daei bath with the dimension of 10.09*16.33 $\mathrm{m}^{2}$ Golden ratio

$$
\text { تكرارى مورداستفاده قرار گيرند. }
$$

نــرمافـزار كـاربردى SketchUp در سـال موردي 1999 در

@ شركت نوياى نast Software of Boulder, Colorado

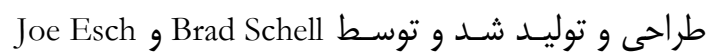

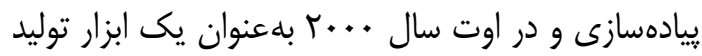

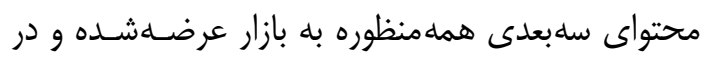

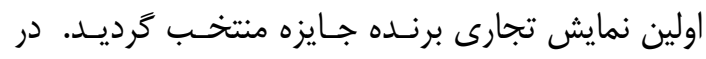

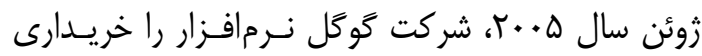

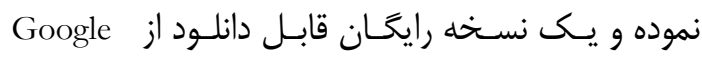
SketchUp

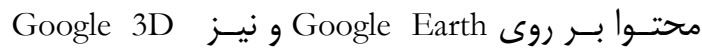
Warehouse

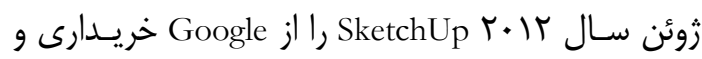

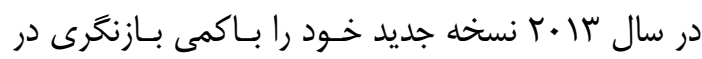
قسمتهاى مختلف مـن جملـه ابزارهـاى ايجـاد كمـان، و و Style Builder

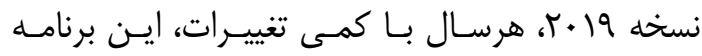

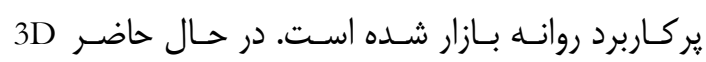
warehouse بار كذارى مدل هاى سلبعدى در Google Earth از سـال

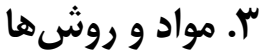

كليه مجسمههاى واقع در دانشعاه هنر اسلامى تبريز بـا

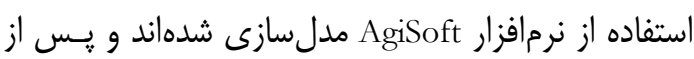

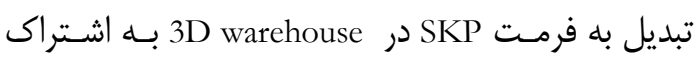

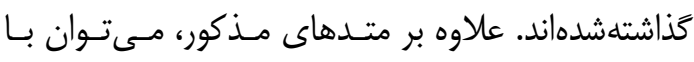

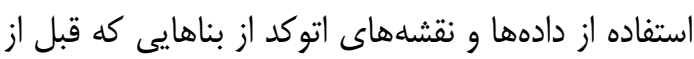

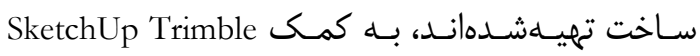

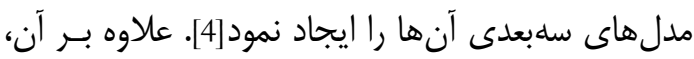

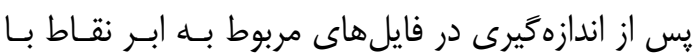
استفاده از اسكنر ليزرى و همين طور نيخاه از بالا در شكل

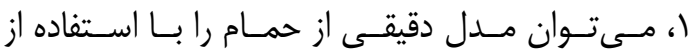

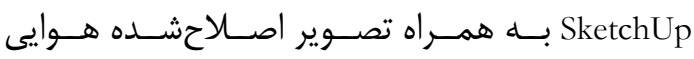
و عوارض زمـين (Orthophoto)

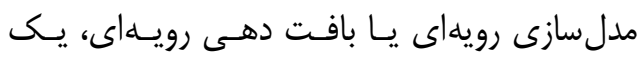
برنامه كاميبوترى جهت توليد خودكار مدلهاى سالبعدى

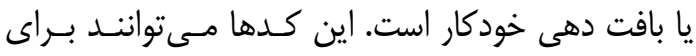

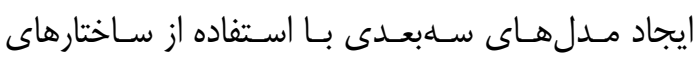
تكرارى مانند برجهاى دوقلوى يتروناس در كوالالاميـور و يا بافتهاى تاريخى با سازهها يا بافتهـاى تصـويرى دئرى 


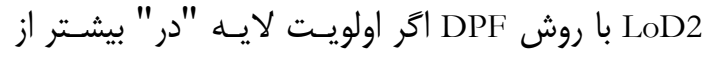

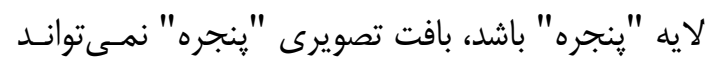

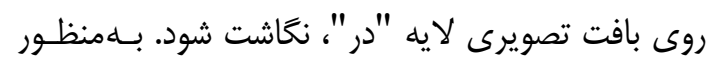
توليد فريم خروجى بـراى DPF، مس بـايست تصـاويرى

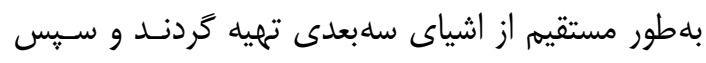

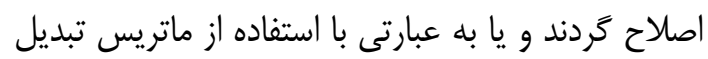
يارالل يروجكشن، خاصيت يرسيكتيو عدسى از تصاوير

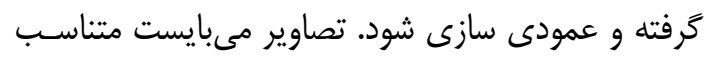
با عرض و ارتفاع نماى هندسه واقعى باشــند تـا بهنـــام

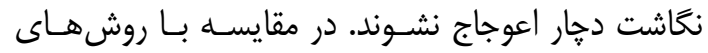
بافت دهى به كمك تصوير واقعى نمـا (Photorealistic)،

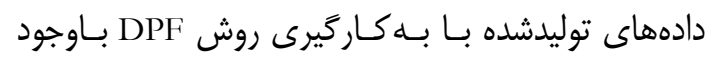
كيفيت بسيار بالا، حجم دادهاى بسيار كمى دارند و براى

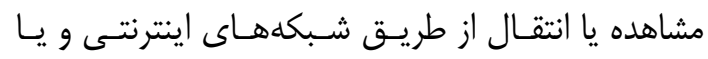

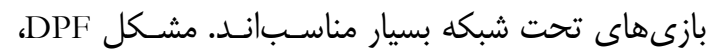

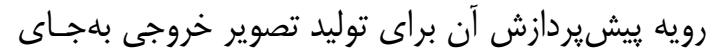

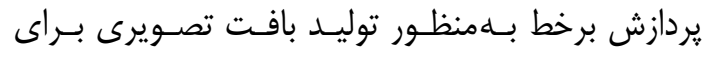

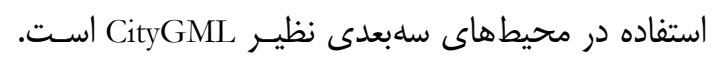

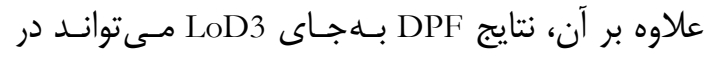

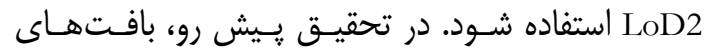

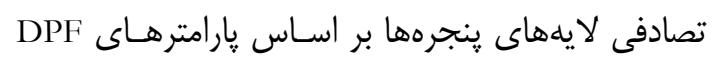

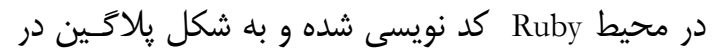

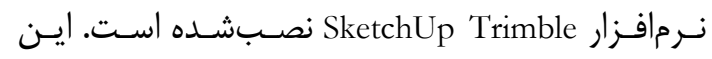

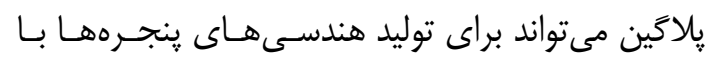

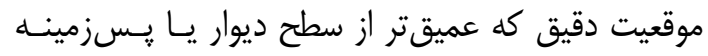

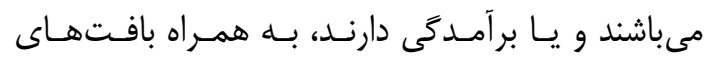

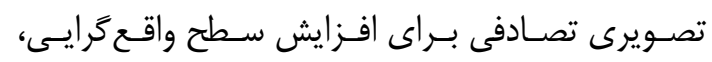

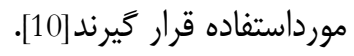

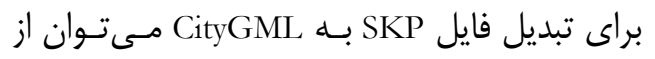

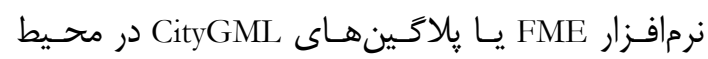
SketchUp Trimble بهره برد. مدل سلبعـدى مفهـومى ترفي

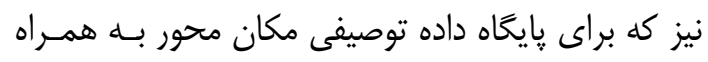

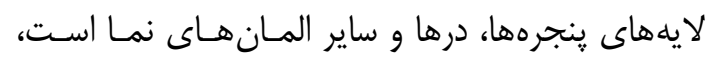

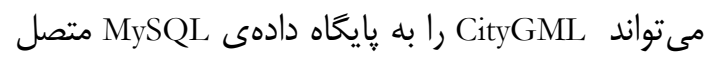

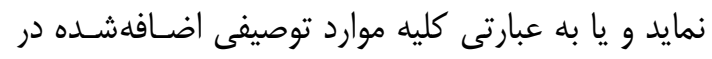

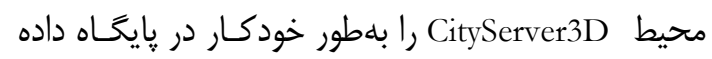
توصيفى MySQL بهنگام سازد[11].

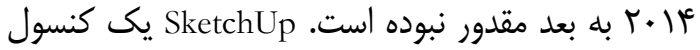

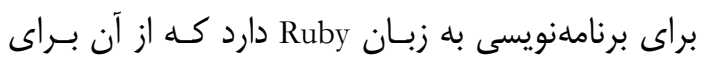

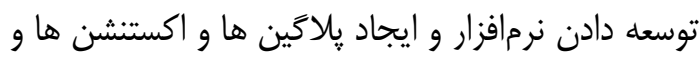

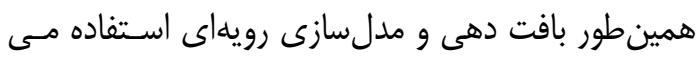

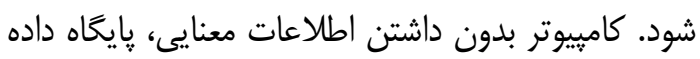
توصيفى مكان محور و كد ليستها جهت نمايـه كـردن

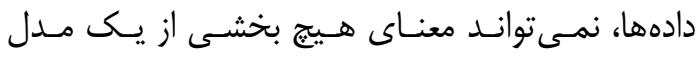

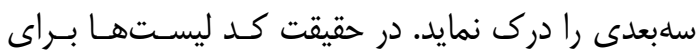

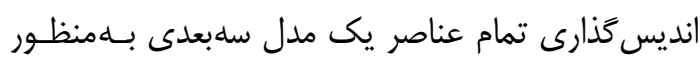

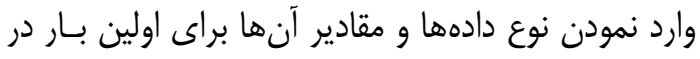

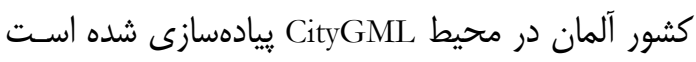

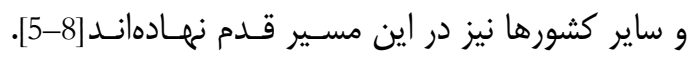

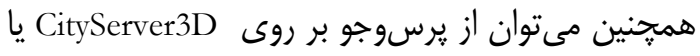

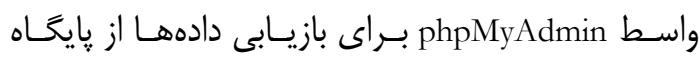
دادههاى MySQL كه بــ CityServer3D متصـل شـده است استفاده نمود. دو نوع سرور ضخيم (Thick server)

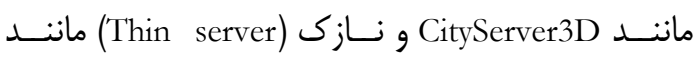
Google Earth وجـود دارنــ[9]. سـرورهاى ضـخيم بـانـا

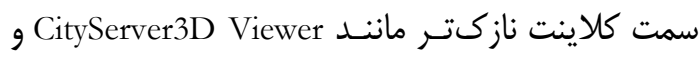

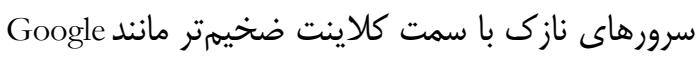
Earth Application مكان محور مربوط به يك مدل سلبعدى دلخواه، با با تمام

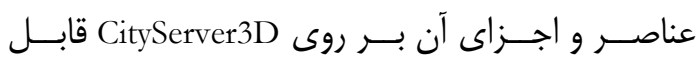

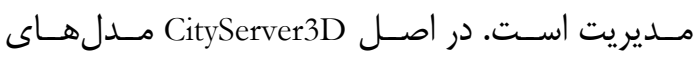

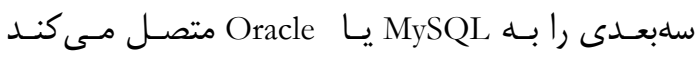

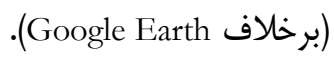

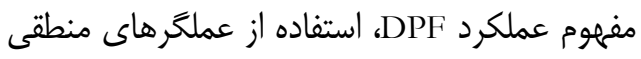
براى نحاشت بافت تصويرى بر روى تصـوير يسـزمينـهـ است كه بلهورت يويايى با مختصات واقعى هندسه بنسا،

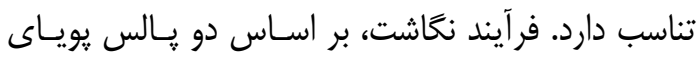

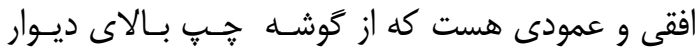

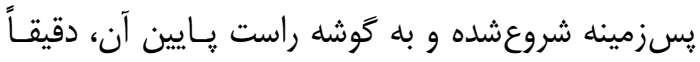
مانند مختصات تصوير، ختم مسى شـود. مقـادير منطقى ونى

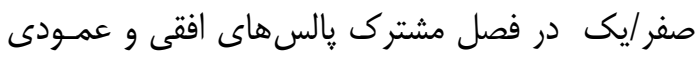

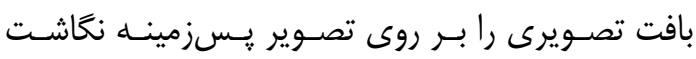

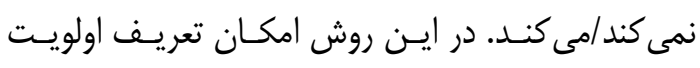
براى هر لايه وجود دارد. بلعنوانمثال در ساخت نماهاى

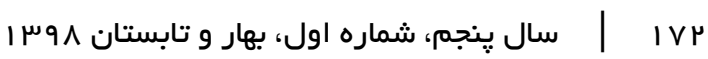


هر قسمت ديخرى از نماى بنـاى تـاريخى كـه بـهـهـور

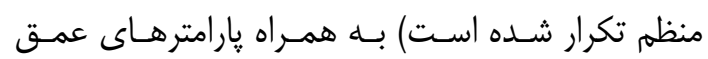

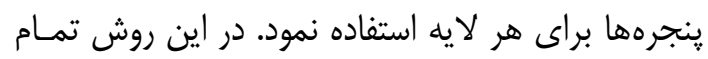

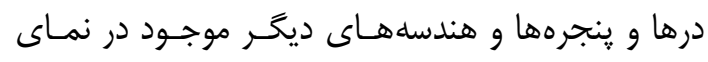

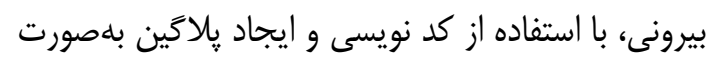

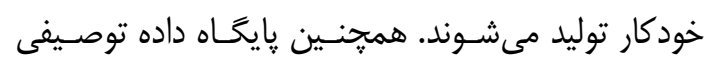

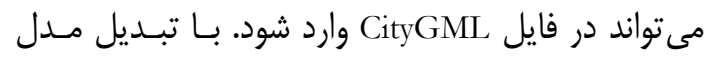

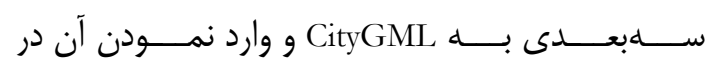
CityServer3D

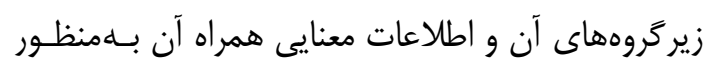

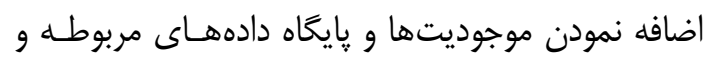

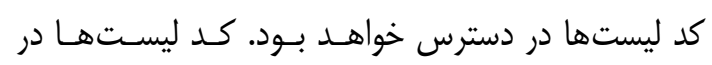

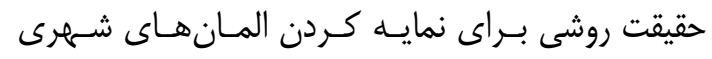

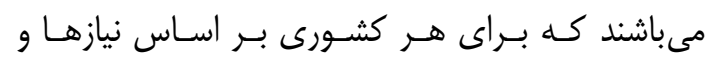

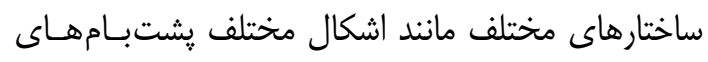

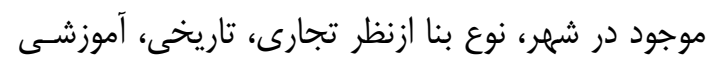

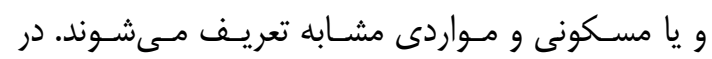

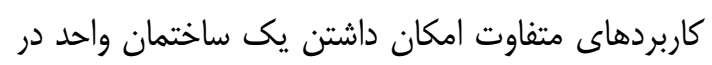
سطوح مختلف جزييات در يك فايل CityGML فـراهم

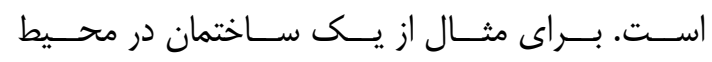
CityServer3D

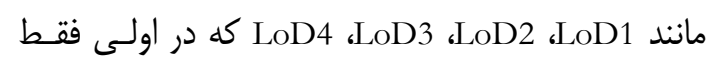
به شكل مكعبى شكل بدون بافت تصويرى و در دومسى

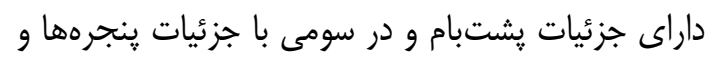

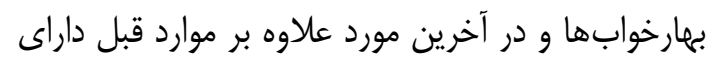

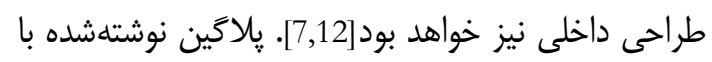

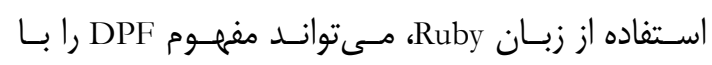

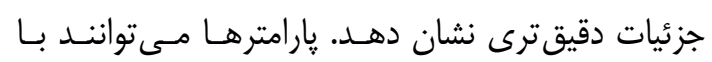

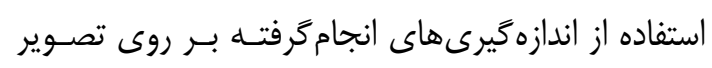

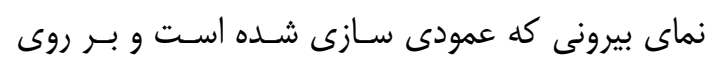

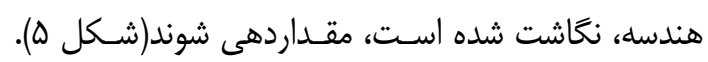

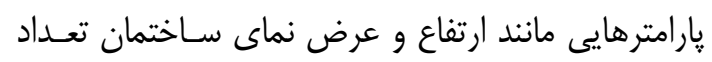

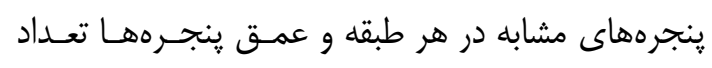

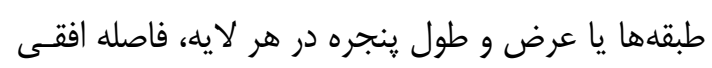

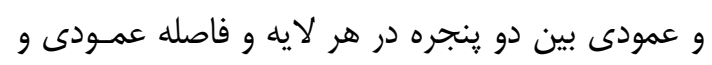

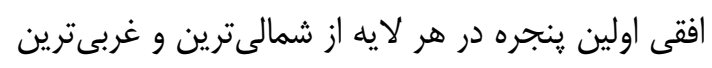

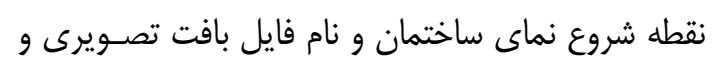

ازآنجـايىكـهـ فـريم خروجـ DPF در تناسـب بـا

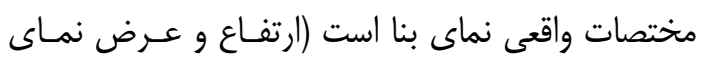
بيرونى)، امكان يرسوجو از يايخـاه داده XML و و تبـديل

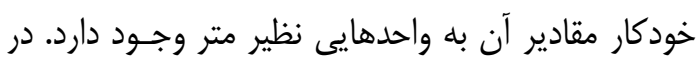

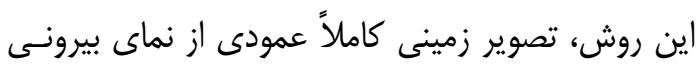

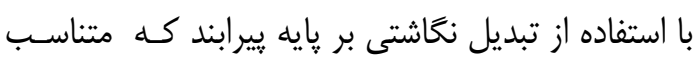

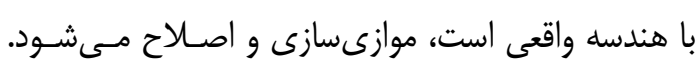

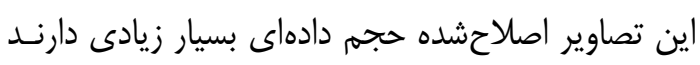

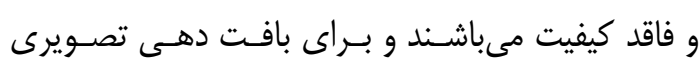

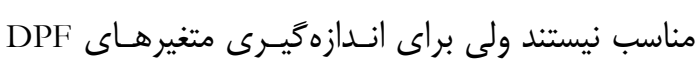

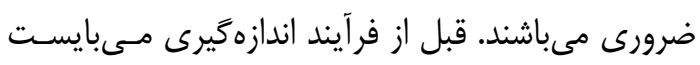

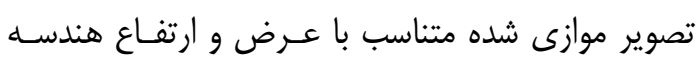

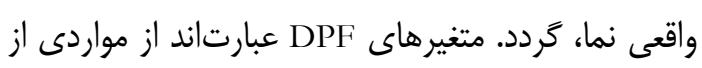
قبيل ارتفاع و عرض نما، ارتفاع و عرض ينجرهـها، درهـا،

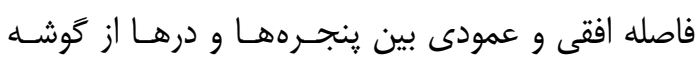

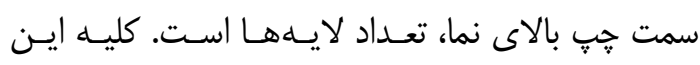
يار امترهاى مى بايست قبل از كد كردن برنامـانه و ايجـاد

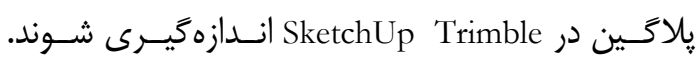

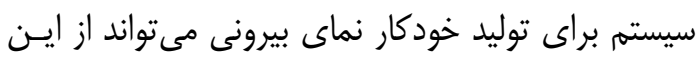

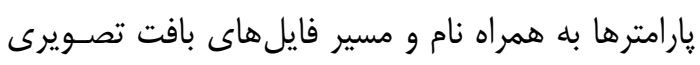

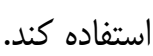

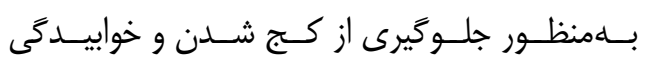

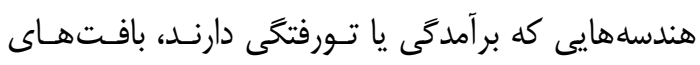

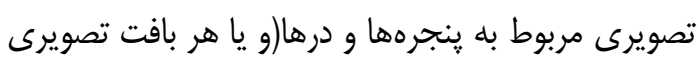

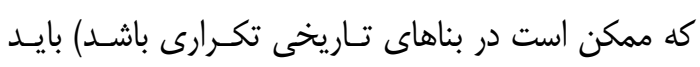

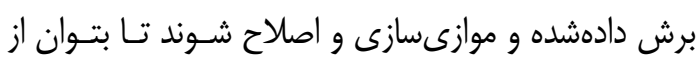

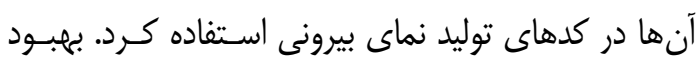

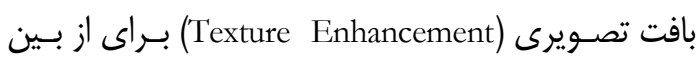

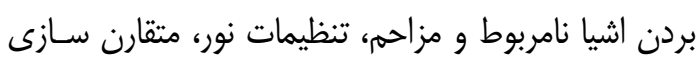

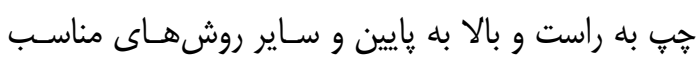

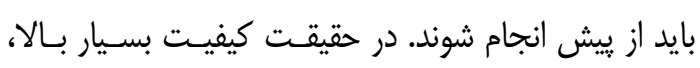

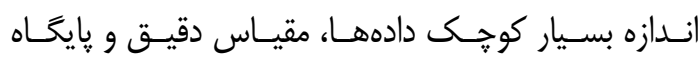

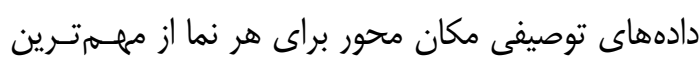

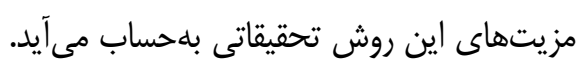

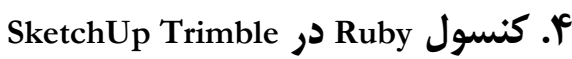

از مفاهيمى مانند DPF مىتوان براى لايه يُنجـره (و يـا

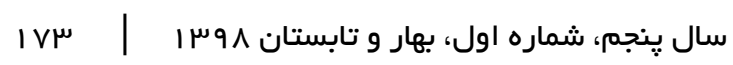



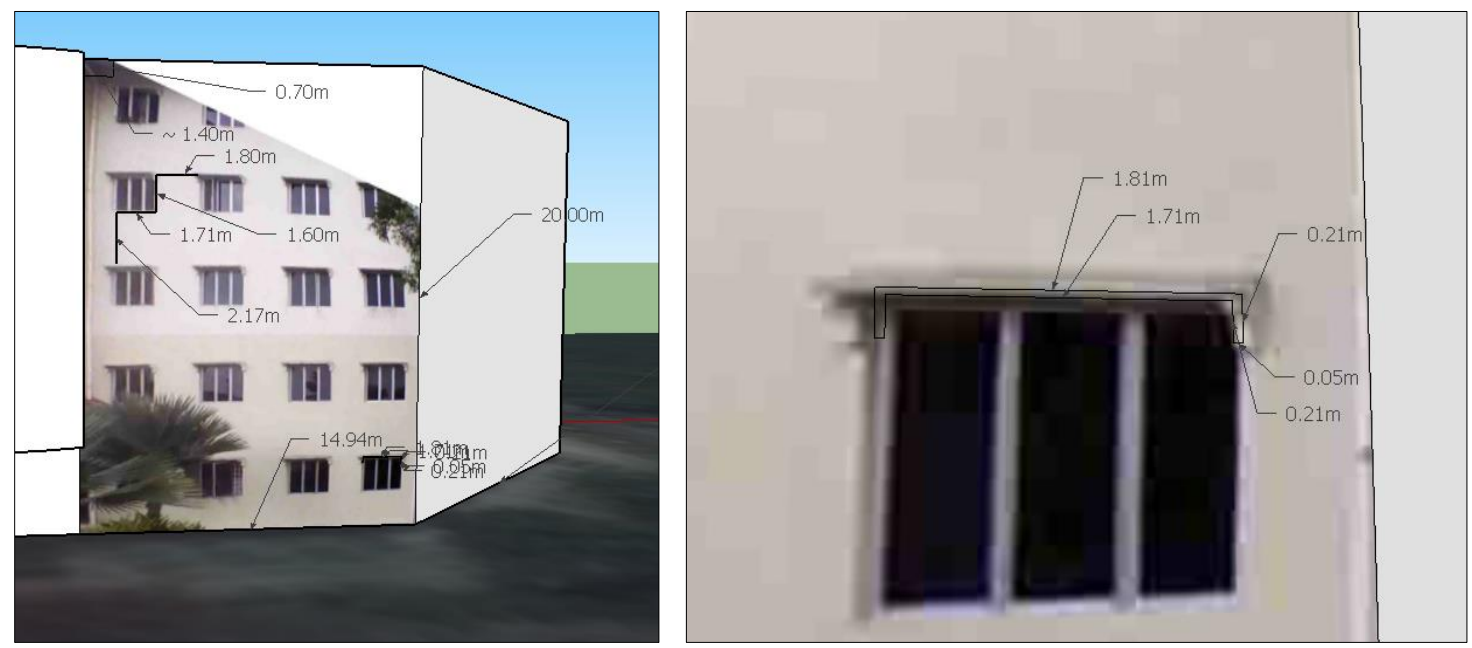

شكل ه: اندازمخيرى يارامترهاى DPF بر اساس تصوير عمودى سازى شده و نغاشت شده بر روى مدل سلبعدى.

Fig. 5: Measuring DPF parameters via orthogonal and projected photo on the 3D model

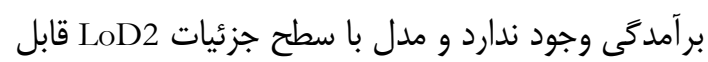
ييادهسازى است[114].

\section{ه. تبديل فرمتها}

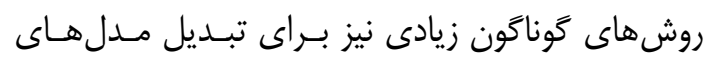

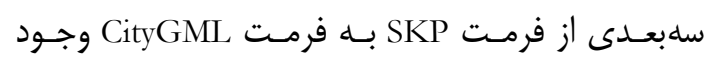

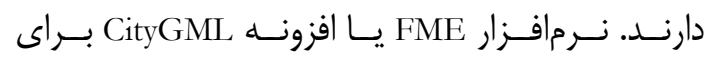

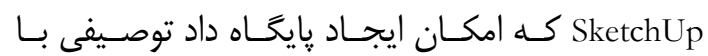
مختصات دقيق جغرافيائى را فراهم مى كنند از مهمترين

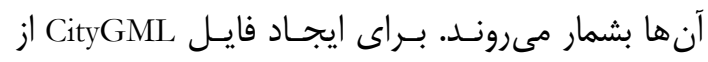

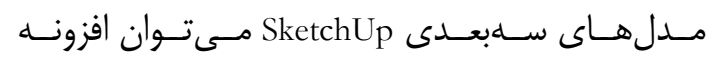

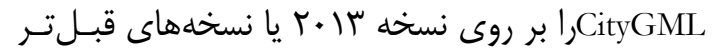

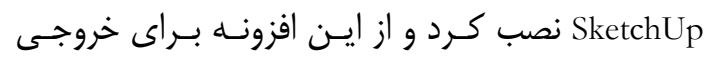

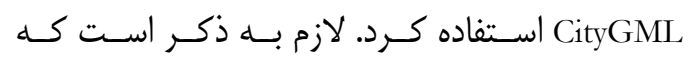

مسير آن براى توليد خودكار نماى بيرونى هندسههايى با

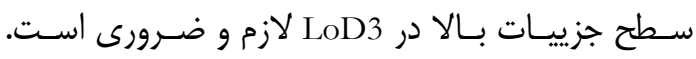
مى توان از بافت تصويرى تصادفى جهت افزايش سـطح واقع گرايى (Level of realism) نيز استفاده كـرد[13]. بـانـا

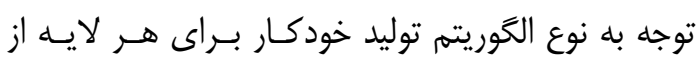

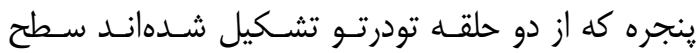

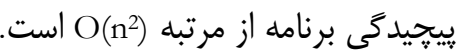

در شكل ه يارامترهاى مربوط به تـابع يـالس يويـا اندازهيرى شدهاند و در داخل برنامه براى ايجاد افزونـهـ

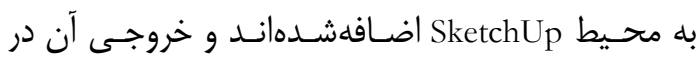

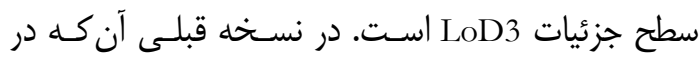

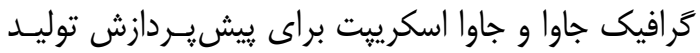

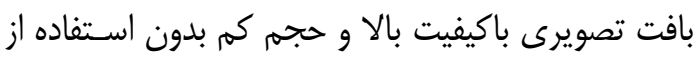

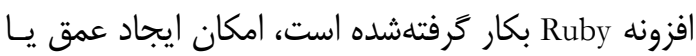

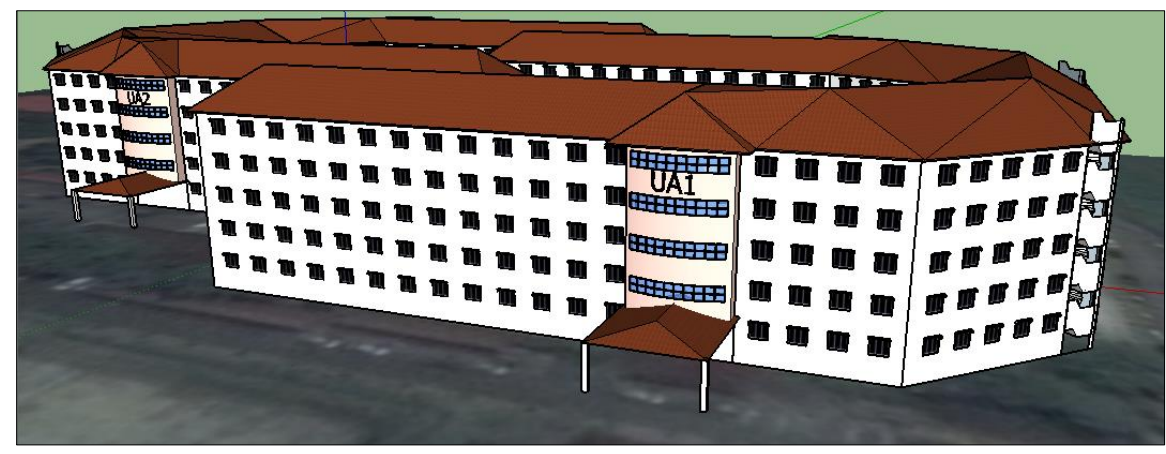

شكل צ: مدل سلبعدى ايجادشده با استفاده از افزونه DPF در محيط SketchUp (كالج ح، دانشگاه يو تى ام مالزى جوهور باهرو)

Fig. 6: The 3D model of Kolej 9, UTM, Johor Bahro via DPF plugin within SketchUp 

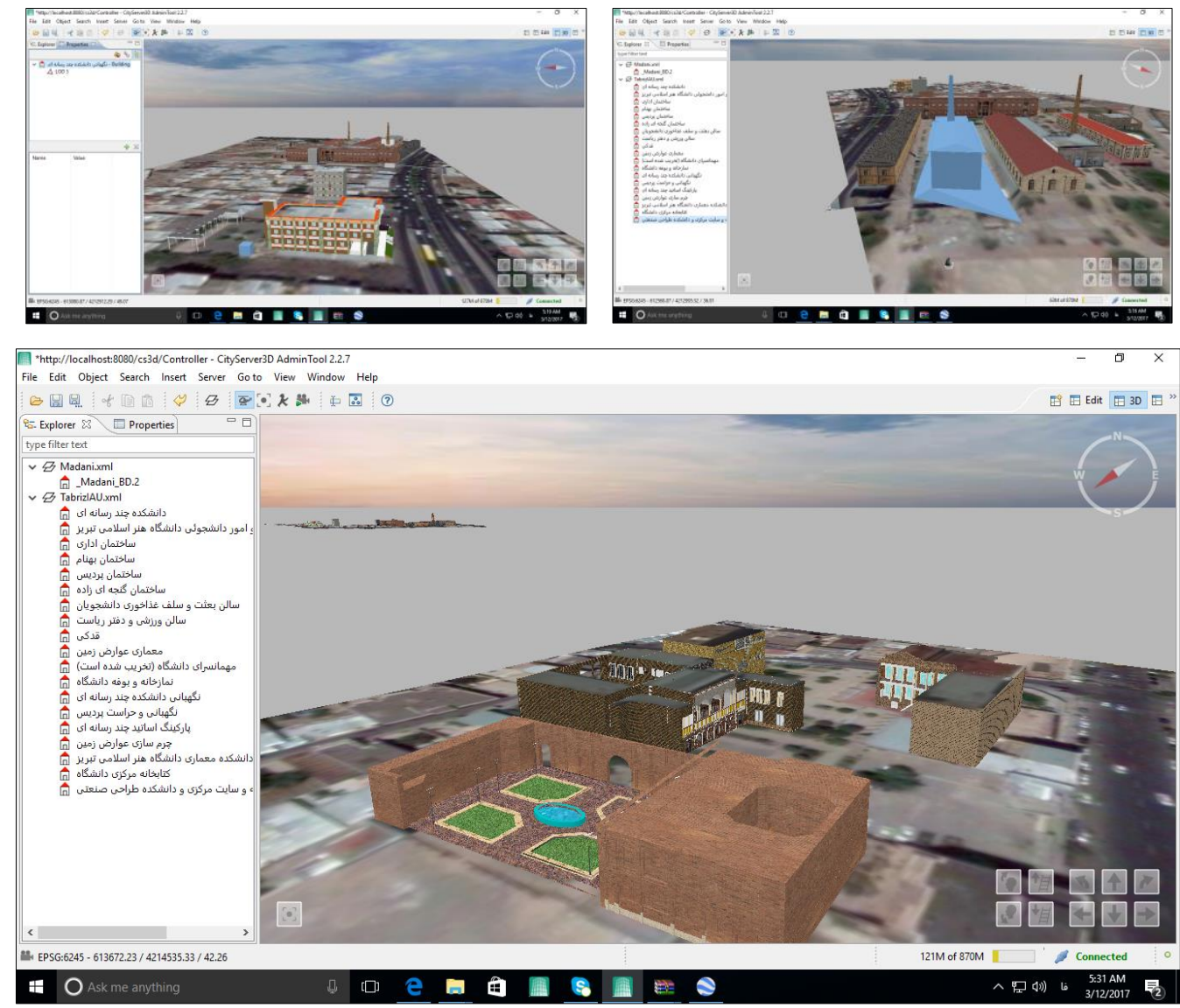

شكل V: مدل سلبعدى دانشكاه هنر اسلامى تبريز با فرمت CityGML در محيط CityServer3D

Fig. 7: The 3D model of Tabriz Islamic Art University in CityGML format, within CityServer3D

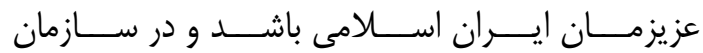
ISO(International Standard Organization) شود. براى مثال كد ليست مربوط به ساختمانهايى كـه

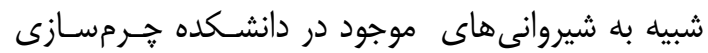

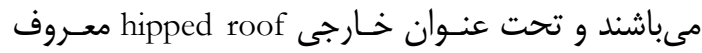

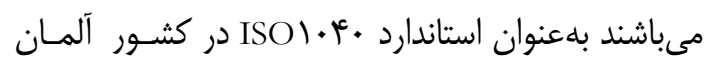
تعريفشدهاند و به ثبت رسيدهانـد. ولى بــــاى برخسى از ساختارهاى كَنبدى شكل و يا شبيه بـهـ يشـتبــام بـازار

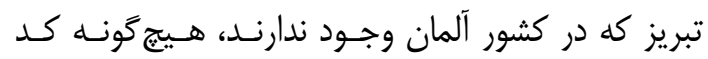
ليستى تعريفنشده است كه ايـن مــوارد را مسىتـوان در

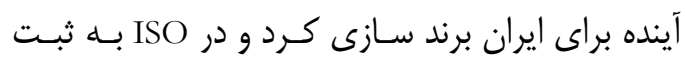

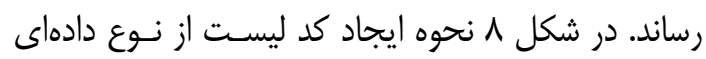

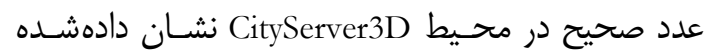
است كه با تعريف نام و مقدار بلهراحتى مى توان از يايڤاه داده توصيفى بر اساس آن جستجو كرد.

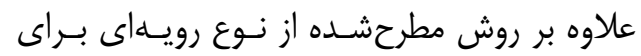

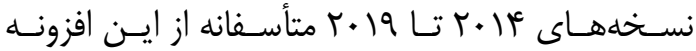

$$
\text { ֶشتيبانى نمى كنند(تصوير V). }
$$

در تبديل فرمتهاى ب بعدى بــهـ يكـديخر معمـولاً

مشكلاتى ايجاد مى گردند (Interoperability problems)

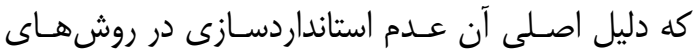
مدلسازى و برنامههاى مرتبط براى مدلسازى مى باشند

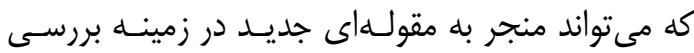

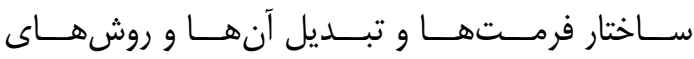

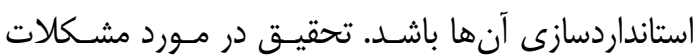
مربوط به تبديل فرمتها و تجزيهوتحليل آنها مى تواند نهايتاً راهكارهاى مفيدى جهت استانداردسازى ارائه دهد.

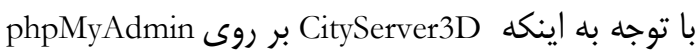

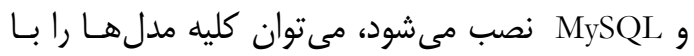

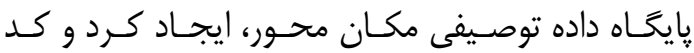

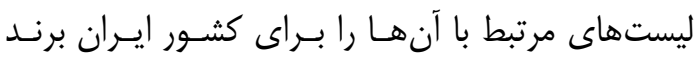

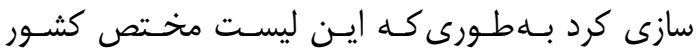

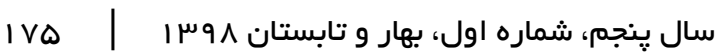




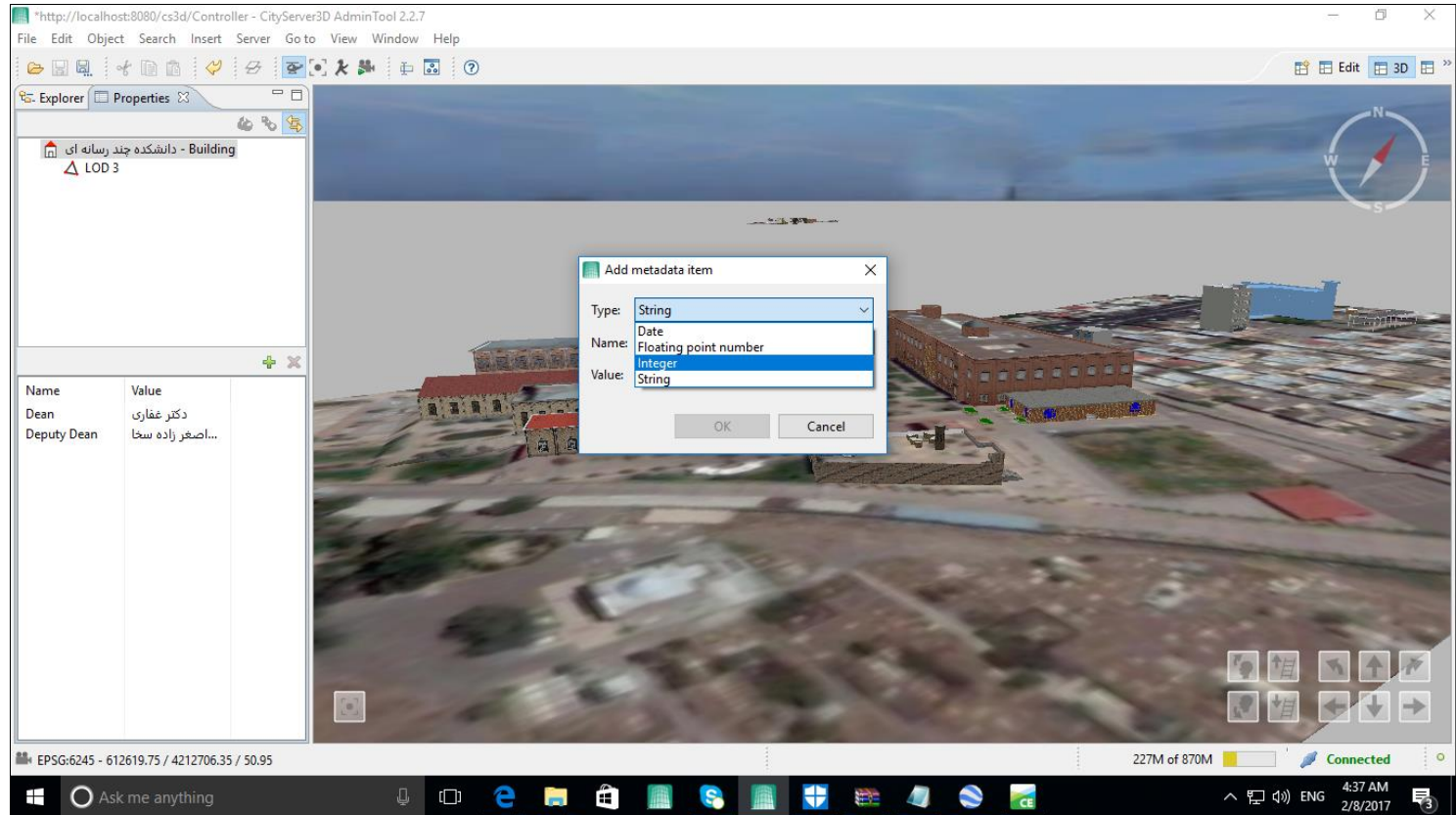

شكل م: نحوه تعريف كد ليست در محيط CityServer3D كه بهطور خودكار در CityGML و پايكاه داده MySQL بهنگام مى شود. Fig. 8: The process of defining code list within CityServer3D that can automatically update CityGML and MySQL DB

\section{و. نتيجلكيرى و دورنماى تحقيق}

با توجه به اينكه اغلب بناهاى تاريخى و باستانى از يـــ

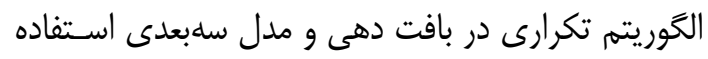

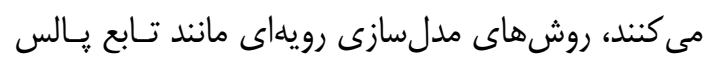

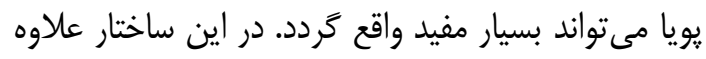
بر دقت بالاى مدل سازى حجم نهائى فايل ازنظر انــازه

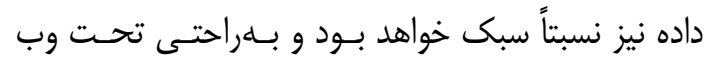

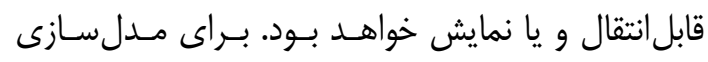

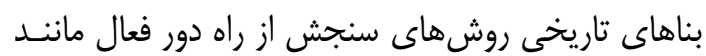
اسكنرهاى ليزى وجود دارند كه حجم داده آنهـا بسـيار زياد است و براى مرمت آثار تـاريخى مورداسـتفاده قـرار
مدلسازى سهبعدى و بافت دهى تصويرى با استفاده از

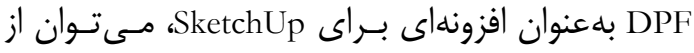

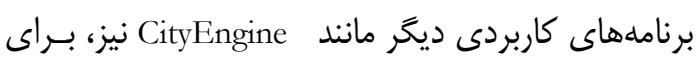

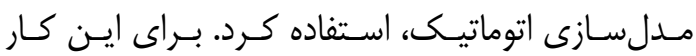
بهراحتى مسى مـوان از openstreetmap يـس از انتخـاب

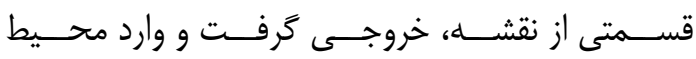
CityEngine

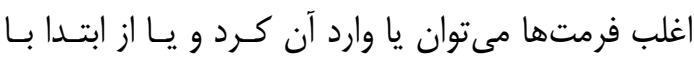
روش رويهاى و كد نويسى CGA ايجاد كرد و درنهايست

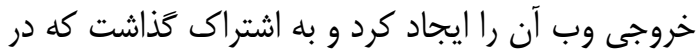

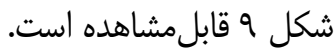
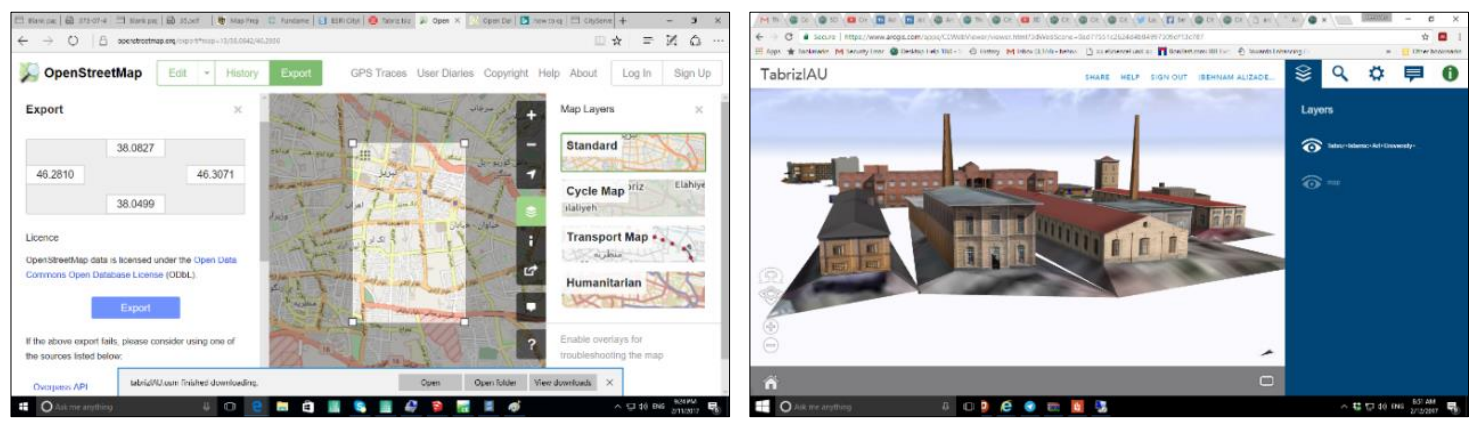

شكل و: نحوه واردكردن مدل سلبعدى در محيط CityEngine و ايجاد خروجى وب براى به اشتراك كذاشتن آن

Fig. 9: The process of exporting map from OpenStreetMap and importing 3D models into CityEngine 


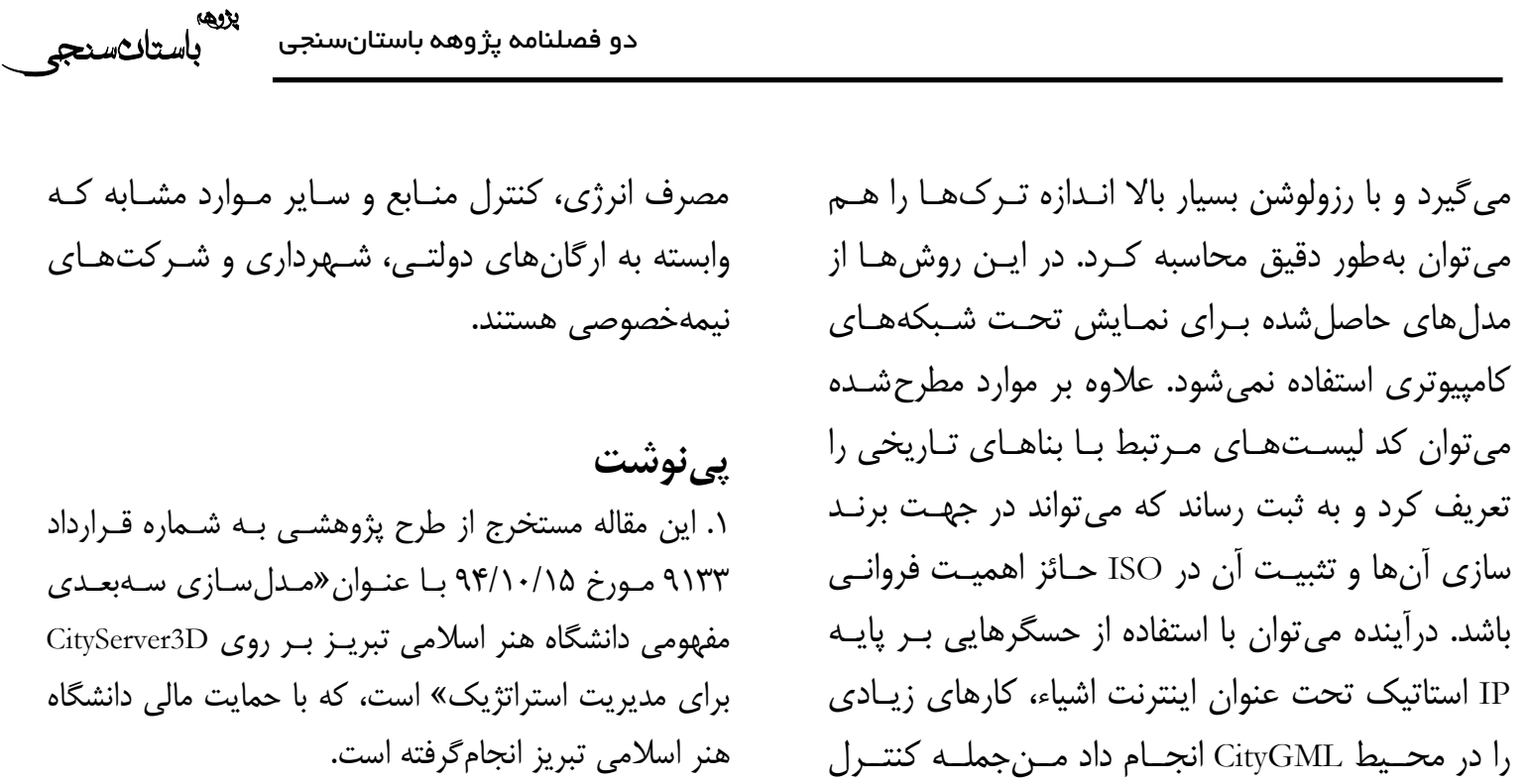

\section{References}

[1] Brutto M Lo, Spera MG. Image-based and range-based 3D modelling of archaeological cultural heritage: the Telamon of the temple of Olympian Zeus in Agrigento (Italy). Int Arch Photogramm Remote Sens Spat Inf Sci 2011;37.

[2] Labetski A, Kumar K, Ledoux H, Stoter J. A metadata ADE for CityGML. Open Geospatial Data, Softw Stand 2018;3:16.

[3] Alizadehashrafi B. Using Parameters of Dynamic Pulse Function for 3D Modeling In LoD3 Based on Random Textures. Int Arch Photogramm Remote Sens Spat Inf Sci 2015;40.

[4] Alizadehashrafi B, Rahman AA. CADbased 3D semantic modeling of Putrajaya. Proc. Jt. ISPRS Work. 3D city Model. Appl. 6th 3D GeoInfo Conf., 2011.

[5] Zadeh PA, Wei L, Dee A, Pottinger R, Staub-French S. BIM-CITYGML data integration for modern urban challenges. J Inf Technol Constr 2019;24:318-40.

[6] Donkers S, Ledoux H, Zhao J, Stoter J. Automatic conversion of IFC datasets to geometrically and semantically correct CityGML LoD3 buildings. Trans GIS 2016;20:547-69.

[7] Kolbe TH, Gröger G, Plümer L.

CityGML: Interoperable access to 3D city models. Geo-information disaster Manag., Springer; 2005, p. 883-99.

[8] Gröger G, Kolbe TH, Nagel C, Häfele $\mathrm{K}-\mathrm{H}$. OGC city geography markup language (CityGML) encoding standard 2012.

[9] Haist J, Coors V. The W3DS-Interface of Cityserver3D. Eur. Spat. Data Res. ua Next Gener. 3D City Model. Work. Pap. Particip. Ed., 2005, p. 63-7.

[10] Scarpino M. Automatic SketchUp: Creating 3-D models in ruby. Eclipse Engineering LLC; 2010.

[11] Alizadehashrafi B, Baig SU. Framework for Malaysian 3D SDI in CityGML. FIG2014 2014.

[12] Arroyo Ohori K, Diakité A, Krijnen T, Ledoux H, Stoter J. Processing BIM and GIS models in practice: experiences and recommendations from a GeoBIM project in the Netherlands. ISPRS Int J Geo-Information 2018;7:311.

[13] Alizadehashrafi B, Rahman AA. Towards Enhancing Geometry Textures of 3D City Elements. Dev. Multidimens. Spat. Data Model., Springer; 2013, p. 135-53.

[14] Alizadehashrafi B, Rahman AA, Coors V, Schulz T. 3D navigation systems based on synthetic texturing 2009. 